\title{
Intelligently Informed Control over the Process Variables of Oil and Gas Equipment Maintenance
}

\author{
Bukhtoyarov Vladimir Viktorovich ${ }^{1,}$, Milov Anton Vladimirovich ${ }^{2, \mathrm{~b}}$, Tynchenko Vadim Sergeevich ${ }^{1, \mathrm{c}^{*}}$, Petrovskiy \\ Eduard Arkadievich ${ }^{1, \mathrm{~d}}$, Tynchenko Sergey Vasilyevich ${ }^{1, \mathrm{e}}$ \\ ${ }^{1}$ Siberian Federal University, Svobodny 79, Krasnoyarsk 660041, Russia \\ ${ }^{2}$ Reshetnev Siberian State University of Science and Technology, 31, Krasnoyarsky Rabochy Av., 660037 Krasnoyarsk, \\ Russia \\ avbukhtoyarov@sfu-kras.ru, ${ }^{\mathrm{b}}$ antnraven@ieee.org, ${ }^{\mathrm{c}}$ vadimond@mail.ru, ${ }^{\mathrm{d}}$ epetrovsky@sfu-kras.ru, ${ }^{\mathrm{e}}$ 051311@mail.ru
}

\begin{abstract}
This article presents the development of a method for identifying non-standard errors in control the technological process of maintenance petroleum equipment using intelligent methods. There is stated a new formulation of the technological process control problem for the maintenance of petroleum equipment as the task of classifying errors introduced by means of measuring the parameters of the technological process. Intellectual methods have proven themselves as a tool for solving the problem of classification. Various intellectual methods were considered for solving the classification problem: decision trees, artificial neural networks and fuzzy logic method. Effectiveness comparison of the proposed methods is carried out on the basis of experimental data on actual technological processes of petroleum equipment maintenance.

The results of the study indicate that the method based on artificial neural networks is the most efficient in solving the problem of classifying the errors of measuring instruments. The proposed method of managing the technological process of petroleum equipment maintenance is intended primarily to improve the repair quality of such equipment components as the pipeline system for transferring hydrocarbon raw materials. Using the proposed method will improve the quality of maintenance work; improve the durability of the pipeline system, which in turn can increase the efficiency of hydrocarbon production.
\end{abstract}

Keywords: Equipment Maintenance, Induction Brazing, Measurement Errors, Intellectual Analysis, Petroleum Equipment

\section{Methods}

\subsection{Introduction}

At present, В настоящее время нефтегазовая отрасль формирует основу бюджета и обеспечивает функционирование oil and gas industry forms the basis for budgeting and ensures the functioning of many other sectors of the economy in Russian Federation. A wide range of petroleum equipment is used to produce, process and refine gas and oil. This includes equipment for drilling and servicing wells, equipment for transporting and processing crude hydrocarbons, as well as measurement and control tools, pumping equipment, components of the pipeline system and so on (Piovesan and Kozman 2014).

Components of the pipeline system are subject to the greatest wear when in service. Corrosion is one of the relevant factors here (Moiseeva 2005). An equally important factor affecting the equipment is the impact of complex environmental conditions:

1. Low temperatures;

2. Daily temperature difference;

3. Wind speed;
4. Environmental humidity;

5. Features of the area geological structure and the nature of the rocks composing it;

6. Relief;

7. Hydrogeological conditions;

8. Permafrost conditions;

9. Current geological processes.

That is especially important for the northern hydrocarbon production regions (Rahimi et al. 2011). Thus, the reliability assessment of the oil and gas equipment for timely maintenance and repairs is an issue of vital importance (Zemenkova et al. 2016; Kersey 2000).

Various heating processes are traditionally used to restore the integrity of the assembly of the pipeline, the main ones being welding and brazing. Welding is the most popular method of repairing and connecting elements of pipeline equipment, as the process is relatively simple and there is no need to use additional consumables. However, welding methods does not always ensure the required quality (Queitsch 1975; Fominykh et al. 2018).

Induction brazing has proven itself useful in various fields of mechanical engineering (Gierth et al. 2012; Mazón-Valadez et al. 2014; Nishimura et al. 1992). 
Developments in the field of aerospace industry have clearly demonstrated the efficiency of induction brazing for the production and maintenance of spacecraft waveguide elements (Murygin et al. 2017a; Tynchenko et al. 2016; Murygin et al. 2017b). In (Gierth et al. 2012; Mazón-Valadez et al. 2014; Nishimura et al. 1992; Murygin et al. 2017a; Tynchenko et al. 2016; Murygin et al. 2017b) reviewed the induction heating technology is proved to ensure the production of items with the quality sufficient for using in difficult operating conditions, such as in space.

The use of induction brazing for oil and gas equipment maintenance allows improving the quality of the pipe joints, and as a result, to increase the reliability of the equipment and the efficiency of hydrocarbon production (Baskin 2012; Ernens et al. 2018).

Automation of induction heating as a part of brazing process is based on measuring the temperature of the brazed elements and the subsequent shaping of control impacts on the generator. It should be noted that currently pyrometry, which principle of operation is based on measuring the power of thermal radiation of an object in the range of infrared radiation, is the most popular method of noncontact temperature measurement. However, a high-tech method like this is associated with various measurement errors in the process of brazing. The quality of measurements is influenced by many factors. One of these factors may be the difference in emissivity of the elements joined. Melting of flux and solder also cause the characteristic error in measuring the temperature within the control process. Noncontact temperature measurement sensors are used in order to avoid violating the integrity of the product in the process of induction brazing; yet some of their specific features (different emissivity values of the base material, solder, and flux; electromagnetic interference from the source of induction heating in the working area) also cause certain measurement errors.

Classical control methods, based on the different variations of the proportional-integral-differential (PID) controller (Murygin et al. 2017a; Tynchenko et al. 2016; Murygin et al. 2017b), do not provide sufficient quality control in the presence of non-normative measurement errors. We suggest the use of intellectual methods to ensure the controllability of the process variables of oil and gas equipment maintenance (Friedman et al. 2001; Witten et al. 2016; Mitchel 1997; Larose and Larose 2005; Breiman 2017).

Intellectual methods allow providing high controllability of process variables of oil and gas equipment maintenance. This is achieved by using the proposed method of the non-standard errors identifying in the process of petroleum equipment maintenance. In essence, this problem is a classification task, which can be solved using intellectual methods (Ripley 1996; Jordan and Rumelhart 1992; Nasrabadi 2007; Lippmann 1987; Fausett 1994; Nelson and Illingworth 1991).

It is necessary to solve the problem of classifying measurement errors arising in the process of repairs through induction heating technology to ensure the controllability of process variables (control algorithms, their coefficients, algorithms switching parameters, etc.) of oil and gas equipment maintenance.

The time series of temperature changes of brazed elements, as well as the information about the pyrometers settings (emissivity coefficients) can be used as inputs of such a classifier.

\subsection{Choosing the Method of Solving the Problem of Classifying Measurement Errors}

Formally, the task of ensuring the controllability of the processes variables for the oil and gas equipment maintenance is a matter of classification. The formal task statement of the classification problem is as follows.

Suppose $X$ is a set of object descriptions and $Y$ is a finite set of class numbers. There is an unknown dependency $y^{*}$ :

$$
y^{*}: X \rightarrow Y
$$

Values are known only as objects of finite learning sample:

$$
X^{m}=\left\{\left(x_{1}, y_{1}\right), \ldots, \quad\left(x_{m}, y_{m}\right)\right\}
$$

It is required to build an algorithm $a$ :

$$
a: X \rightarrow Y
$$

which can classify an arbitrary object $x$ out of $X$.

The task of classifying the errors of measurement tools is related to the subfield of machine learning, called learning with a teacher (Loh 2011).

Machine learning is a large subsection of artificial intelligence studies that deals with methods for constructing algorithms capable of learning (Ripley 1996).

Two types of learning are traditionally distinguished:

1. Case study based on the identification of general regularities in particular empirical data;

2. Deductive training, involving the formalization of expert knowledge and their transfer to information systems in the form of a knowledge base. (Witten et al. 2016)

The task of classifying non-normative errors of measurement tools according to the type of training is relevant to tasks with learning with the teacher (deductive training).

Learning with the teacher is one of the subfields of machine learning associated with solving the following task: there are many objects (situations) and many possible answers (responses, reactions) (Hastie et al. 2009; Mitchell 1997). There is some correlation between answers and objects, but it is unknown. Only a 
finite set of precedents is known: the "object - response" pairs called the training set. It is required, basing on set of precedents, to restore the dependency, that is, to build an algorithm capable of producing a reasonably accurate answer for any kind of object. A quality functional is introduced to measure the accuracy of these answers. Quality functional indicates the degree of the recognition accuracy of a teaching example in parts.

According to the type of input data, the task of classifying non-normative errors of measuring instruments is relevant to the tasks with input time series, which are sequences of measurements of process variables over time. In general, each measurement is an indicative description of the process over time.

The main methods for solving the classification problem are:

1. Decision trees;

2. Artificial neural networks;

3. Fuzzy logic.

\subsection{Decision Trees}

Decision trees reproduce logical patterns that allow one to obtain a final decision on the classification of an object, using answers to a hierarchically organized system of questions. And the question asked at the subsequent hierarchical level depends on the answer received at the previous level (Breiman 2017; Loh 2011). Similar logical models have long been used in botany, zoology, mineralogy, medicine and other fields. Each of the tree's nodes, with the exception of the leaves, corresponds to a certain question, implying several possible answers corresponding to the branches. Depending on the selected answer option, you are taken to the node of the next level. The end nodes are associated with labels indicating the assignment of an identifiable object to one of the classes. A deciding tree is called binary if each inner or root node is incident with only two branches. Binary trees are convenient to use in machine learning models. (Loh 2011)
Classifier visualization with the use of decision tree can be seen on Fig. 1.

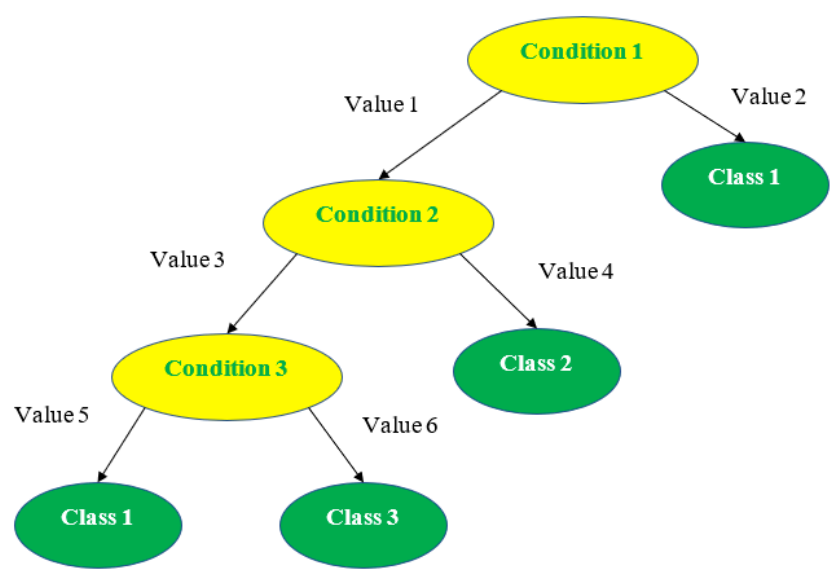

Fig. 1. An example of the decision tree classifier

When carrying out experimental studies of decision trees applicability, the task was to classify the errors of measuring instruments as follows: 72 input parameters, of which the first 60 are the time series of changes in the temperatures of the brazed elements, while the remaining 12 are the values of the pyrometers emissivity coefficients. The class forming feature is the presence of an error with four possible values:

1. "Non-normative errors exist" - measurement error was detected that has a significant impact on the quality of process control;

2. "Non-normative errors don't exist";

3. "Normative errors exist" - measurement error was detected that has little effect on the quality of process control;

4. "Normative errors don't exist".

The contingency the classifier, built on the basis of decision trees, is presented in Table I.

Contingency table shows us that the efficiency of the decision trees method in solving the classification problem is $80.52 \%$.

TABLE I

MODEL'S CONTINGENCY BASED ON DECISION TREES

\begin{tabular}{|c|c|c|c|c|c|c|}
\hline \multirow[t]{2}{*}{ Predicted Value } & \multicolumn{6}{|l|}{ Actual Value } \\
\hline & $\begin{array}{l}\text { Non-Normative Errors } \\
\text { Exist }\end{array}$ & $\begin{array}{l}\text { Non-Normative Errors } \\
\text { Don't Exist }\end{array}$ & $\begin{array}{l}\text { Normative } \\
\text { Exist }\end{array}$ & Errors & Normative Errors Don't Exist & Total \\
\hline $\begin{array}{l}\text { Non-Normative } \\
\text { Errors Exist }\end{array}$ & 73 & 1 & 3 & & 6 & 83 \\
\hline $\begin{array}{l}\text { Non-Normative } \\
\text { Errors Don't } \\
\text { Exist }\end{array}$ & 2 & 76 & 5 & & 4 & 87 \\
\hline $\begin{array}{l}\text { Normative } \\
\text { Errors Exist }\end{array}$ & 15 & 2 & 96 & & 8 & 121 \\
\hline $\begin{array}{l}\text { Normative } \\
\text { Errors Don't } \\
\text { Exist }\end{array}$ & 2 & 1 & 41 & & 127 & 171 \\
\hline Total & 92 & 80 & 145 & & 145 & 462 \\
\hline
\end{tabular}




\subsection{Artificial Neural Networks}

Artificial neural networks can be regarded as both mathematical models and their software or hardware implementations, developed on the principle of organization and the functioning of biological neural networks that is networks of nerve cells in a living organism. This concept appeared in a study of the processes occurring in the brain and the ways of simulating these processes. (McCulloh and Pitts 1943) The first computational model for neural networks was developed by McCulloch and Pitts (1943; 1945). Subsequently, after learning algorithms were developed, the resulting models were used for practical purposes, which include forecasting, pattern recognition, control issues and so on.

Artificial neural networks are a system of simple processors (artificial neurons) connected to and interacting with each other. Such processors are usually quite simple, especially in comparison with the processors used in personal computers. Each processor of a similar network deals only with signals that it periodically receives and those that it periodically sends to other processors. Nevertheless, being connected to a fairly large network with controlled interaction, together these locally simple processors are capable of performing rather complex tasks.
From the point of view of machine learning, a neural network is a special case of pattern recognition, discriminant analysis, clustering methods and so on. From a mathematical point of view, neural networks learning is a multi-parameter problem of nonlinear optimization. Multi-criteria optimization problem is to find a vector of target variables that satisfies the imposed constraints and optimizes a vector function, the elements of which correspond to the objective functions. These functions form the mathematical description of the objective criterion and are generally competitive. Hence, "to optimize" means to find such a solution for which the value of the objective functions would be acceptable for the problem solver.

Neural networks are not programed in the usual sense of the word; rather, they learn. The possibility of learning is one of the main advantages of neural networks over traditional algorithms. Technically, learning means finding the coefficients of connections between neurons. In the process of learning, a neural network is able to detect complex dependencies between input data and output data and perform generalizations. Thus, if learning is successful, the network can return the correct result based on data that were missing in the learning set, as well as incomplete and/or noisy, partially distorted data (Ripley 1996; Jordan and Rumelhart 1992; Nasrabadi 2007; Lippmann 1987; Fausett 1994; Nelson and Illingworth 1991).

An example of a typical structure of an artificial neural network is shown in Fig. 2.

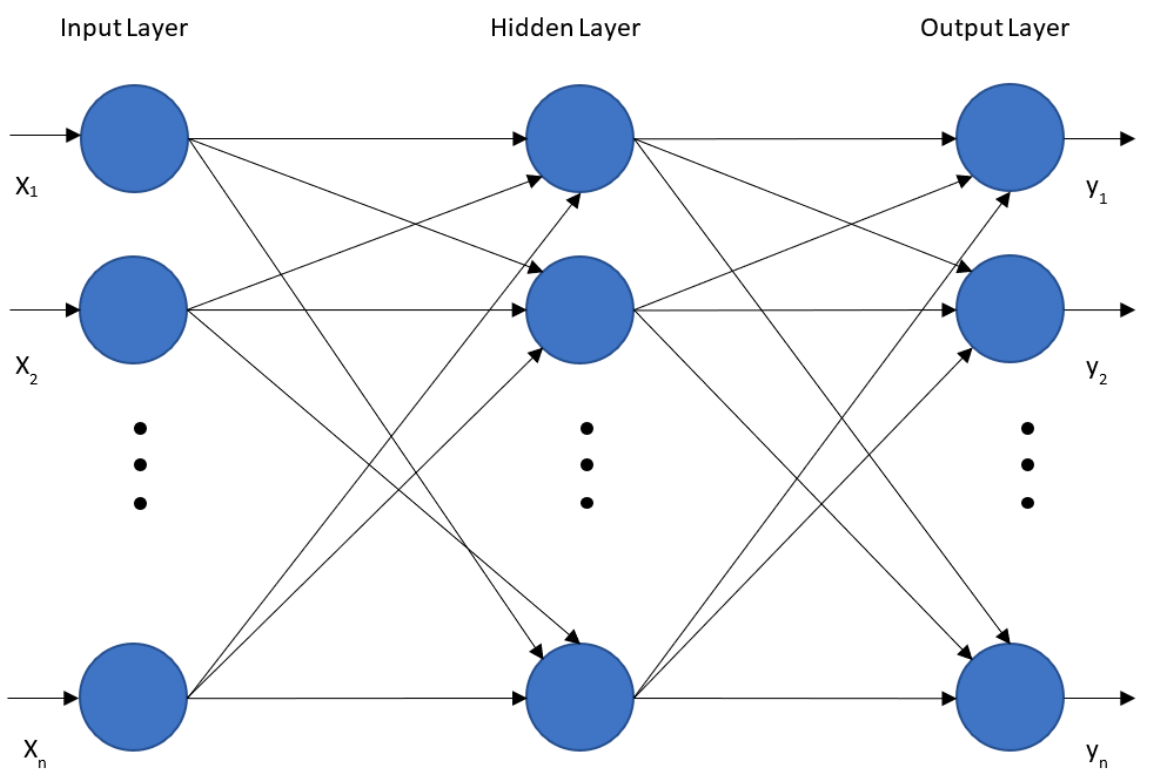

Fig. 2. An example of a typical structure of an artificial neural network with $\mathrm{x}_{1}, \mathrm{x}_{2}, \ldots, \mathrm{x}_{\mathrm{n}}$ as inputs and $\mathrm{y}_{1}, \mathrm{y}_{2}, . ., \mathrm{y}_{\mathrm{n}}$ as network outputs

A typical structure of an artificial neural network is shown in Figure 2. An artificial neural network consists of relatively simple computational elements called neurons. A neuron main function is to receive and transmit signals to the next layer. During training procedure connections between neurons are correlated with weight coefficients which basically determine the importance of a parameter for classifying. A structure of a neural network can be divided into several components. There are input and output variables. Input 
variables are feature descriptions, based on which the classification is performed. Output variables are parameters that define classes. Input data are normalized and screened out according to their importance at the input layer. Class determination is performed by signal propagation through hidden (intermediate) layers for each pattern using the weight coefficients determined during training. An artificial neural network is trained on labeled "sign - class" sets.

Table II presents the contingency table for the classifier model based on an artificial neural network with the structure:
5. 72 variables are input:

a. inputs 1-60: time series of the temperature changes in brazing elements;

b. inputs 61-72: emissivity coefficients of pyrometers;

6. A hidden layer with 16 neurons;

7. 2 variables at the output: 1st class corresponds to the presence of the error, 2nd class specifies error's type.

TABLE II

CONTINGENCY TABLE FOR THE MODEL BASED ON AN ARTIFICIAL NEURAL NETWORK

\begin{tabular}{|c|c|c|c|c|c|}
\hline \multirow[t]{2}{*}{ Predicted Value } & \multicolumn{5}{|c|}{ Actual Value } \\
\hline & $\begin{array}{l}\text { Non-Normative } \\
\text { Errors Exist }\end{array}$ & $\begin{array}{c}\text { Non-Normative Errors } \\
\text { Don't Exist }\end{array}$ & Normative Errors Exist & $\begin{array}{c}\text { Normative Errors } \\
\text { Don't Exist }\end{array}$ & Total \\
\hline $\begin{array}{l}\text { Non-Normative } \\
\text { Errors Exist }\end{array}$ & 88 & 1 & 1 & 2 & 92 \\
\hline $\begin{array}{l}\text { Non-Normative } \\
\text { Errors Don't Exist }\end{array}$ & 1 & 75 & 1 & 3 & 80 \\
\hline $\begin{array}{ll}\text { Normative } & \text { Errors } \\
\text { Exist } & \\
\end{array}$ & 2 & 3 & 141 & 5 & 151 \\
\hline $\begin{array}{ll}\text { Normative } & \text { Errors } \\
\text { Don't Exist } & \end{array}$ & 1 & 1 & 2 & 135 & 139 \\
\hline Total & 92 & 80 & 145 & 145 & 462 \\
\hline
\end{tabular}

Contingency table shows us that the efficiency of the artificial neural network method in solving the classification problem is $95.02 \%$.

\subsection{Fuzzy Logic}

Currently, fuzzy logic is a commonly used tool for solving problems in classification, control, and decisionmaking (Kersey 2000). Among the main advantages of using this method are:

1. the possibility of rejecting complex control systems whenever the required accuracy of the calculations allows it;

2. the description of the decision-making process occurs in natural language (natural language or ordinary language is any language that has evolved naturally in humans through use and repetition without conscious planning or premeditation.) using common human qualitative assessments, and these assessments are linked to a rigorous mathematical apparatus.

The initial classification problem is set using a fuzzy knowledge base, with the characteristics of the process represented as linguistic variables with given membership functions. A membership function is a curve that defines degree of membership of each element of the input space to the fuzzy set. The fuzzy knowledge base, which is developed by an expert, has the following structure:

$$
\text { if ... and (or) ..., then .... }
$$

The problem is solved with the use of Mamdani fuzzy inference (Widrow et al. 1988; Klir and Yuan 1995; Yen and Langari 1999; Mamdani and Assilian 1975).

A visualization of the classifier based on fuzzy logic is presented in Fig. 3. As shown in Figure 3 the input variable is crisp. Then its value is fuzzified using fuzzification procedure. It means that the input variable value which is crisp is transformed fuzzy value. The purpose of fuzzification is to define conformity between elements of crisp (classical) set and the value of membership function of corresponding linguistic variable term. After fuzzification procedure values of membership functions for each term of linguistic variables are to be defined for each crisp input value. All terms of linguistic variables which are used in subconditions of the fuzzy inference system rule base should be considered. Then a fuzzy output variable is evaluated using fuzzy inference rule base and defuzzified into crisp value.

When conducting experimental studies regarding the fuzzy logic methods, we set the task of classifying the errors of measuring instruments as follows: six input variables were temperature differences between adjacent pyrometers on brazed elements of the repaired area of the process equipment. The number of input variables is defined due to configuration of pyrometric sensors located around the pipelines of technological equipment. The six input variables cover the operational data on the technological process throughout the zone of 
the joint between the structural elements of the pipeline assembly. The output is a class of the measurement error. Each of the input variables is checked for being contained in the following terms:

1. ZE (the value of the temperature difference does not exceed the permissible level of deviations);

2. NS, PS (the value of the temperature difference exceeds the permissible level of deviations; moderate deviation of the process variables);

3. NM, PM (the difference value is large; there is significant deviation in the process variables).

Each of the output variables is checked for being contained in the following terms:
1. NNE (Non-normative errors exist);

2. NNDE (Non-normative errors do not exist);

3. NE (Normative errors exist);

4. NDE (Normative errors do not exist).

The rule base was created with the assistance of an expert in the domain area and contains 45 fuzzy logic rules. The optimal number of rules in the rule base is obtained empirically by the expert in the subject area.

A classifier model was learned based on fuzzy logic methods and experimentally obtained data. A contingency table representing this model is presented in Table III.

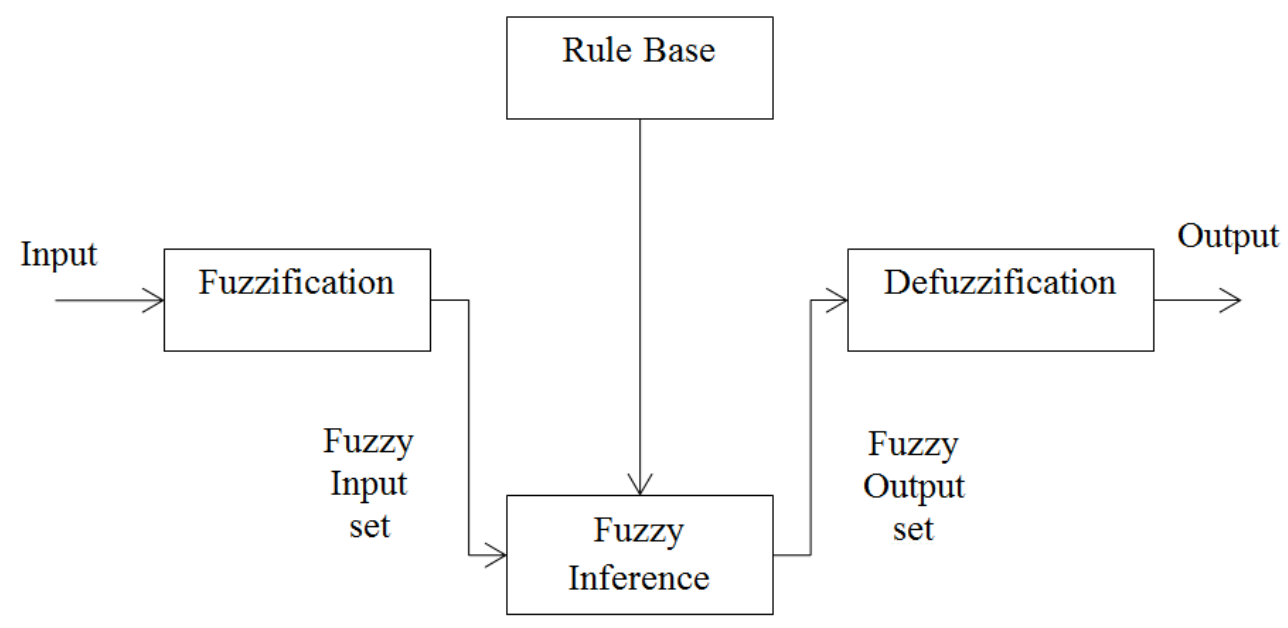

Fig. 3. An example of a classifier based on fuzzy logic

TABLE III

CONTINGENCY TABLE FOR THE MODEL BASED ON FUZZY LOGIC

\begin{tabular}{|c|c|c|c|c|c|}
\hline \multirow[t]{2}{*}{ Predicted Value } & \multicolumn{5}{|c|}{ Actual Value } \\
\hline & $\begin{array}{c}\text { Non- } \\
\text { Normative } \\
\text { Errors Exist }\end{array}$ & $\begin{array}{l}\text { Non-Normative Errors } \\
\text { Do Not Exist }\end{array}$ & $\begin{array}{c}\text { Normative Errors } \\
\text { Exist }\end{array}$ & $\begin{array}{c}\text { Normative Errors Do } \\
\text { Not Exist }\end{array}$ & Total \\
\hline $\begin{array}{l}\text { Non-Normative Errors } \\
\text { Exist }\end{array}$ & 77 & 4 & 2 & 7 & 90 \\
\hline $\begin{array}{l}\text { Non-Normative Errors } \\
\text { Do Not Exist }\end{array}$ & 4 & 69 & 6 & 14 & 93 \\
\hline Normative Errors Exist & 8 & 5 & 134 & 9 & 156 \\
\hline $\begin{array}{l}\text { Normative Errors } \text { Do } \\
\text { Not Exist }\end{array}$ & 3 & 2 & 3 & 115 & 123 \\
\hline Total & 92 & 80 & 145 & 145 & 462 \\
\hline
\end{tabular}

The contingency table shows us that the efficiency of the fuzzy logic in solving the classification problem was $80.08 \%$.

We had to carry out a comparative analysis of the selected methods in order to determine the most efficient method for classifying non-normative errors of measuring instruments. The results are presented in Table IV. 


\begin{tabular}{|c|c|c|c|c|c|}
\hline \multirow[t]{2}{*}{ Predicted value } & \multicolumn{5}{|c|}{ Probability of correct classification } \\
\hline & $\begin{array}{l}\text { Non-normative } \\
\text { errors exist }\end{array}$ & $\begin{array}{c}\text { Non-normative errors } \\
\text { do not exist }\end{array}$ & Normative errors exist & $\begin{array}{c}\text { Normative errors do } \\
\text { not exist }\end{array}$ & Total \\
\hline Fuzzy logic & $83.7 \%$ & $86.3 \%$ & $92.4 \%$ & $79.3 \%$ & $85.4 \%$ \\
\hline Artificial neural network & $95.6 \%$ & $93.8 \%$ & $97.2 \%$ & $93.1 \%$ & $94.9 \%$ \\
\hline Decision tree & $79.3 \%$ & $95 \%$ & $66.2 \%$ & $87.6 \%$ & $82 \%$ \\
\hline
\end{tabular}

The comparative research results are presented in Table IV. The results allow concluding that the efficiency of the method based on artificial neural networks is significantly higher than efficiency of methods based on decision trees and fuzzy logic. Based on this we concluded that the method based on artificial neural networks is the most appropriate and effective for solving the problem of classifying measurement errors in comparison to other examined methods.

Artificial neural networks are the most promising and powerful tool for solving the classification problem. An artificial neural network classifier can show the best results as compared to the other two classification methods presented.

\section{Experimental Studies}

Experiments were conducted on seven models with different numbers of hidden layers to determine the optimal structure of the artificial neural network comprising the learning. The experiments were carried out using the experimental database stored in the course of real technological processes.

The general model structure is:

1. 72 input variables:

a. inputs 1-60: time series

b. inputs 61-72: pyrometers' emissivity coefficients

2. 2 output variables: 1 st class corresponds to the presence of the error, and 2nd class specifies the error type.

The choice of such a number of input variables is due to the fact that for the solution of the problem it is important to take into consideration not temperature values on the soldered pipe assembly elements but temperature variations. Concerning this the elements of the time series containing measured values of temperature variations during process is used as input patterns for the neural network. It was experimentally obtained that the optimal time lag for input consideration is 60 seconds. Another 12 input variables represent the emissivity values for each of the pyrometric sensors.

A sigmoid function was used as an activation function which is monotonically differentiable S-shaped nonlinear function with saturation. Sigmoid allows you to amplify weak signals and not be saturated with strong signals.

The number of hidden layers varied with each set of experiments:

1. $1^{\text {st }}$ set of experiments: one neuron on one hidden layer

2. $2^{\text {nd }}$ set of experiments: two neurons on one hidden layer

3. $3^{\text {rd }}$ set of experiments: two neurons on two hidden layers

4. $4^{\text {th }}$ set of experiments: three neurons on three hidden layers

5. $5^{\text {th }}$ set of experiments: four neurons on four hidden layers

6. $6^{\text {th }}$ set of experiments: five neurons on five hidden layers

7. $7^{\text {th }}$ set of experiments: six hidden neurons on six hidden layers

The results for choosing the optimal structure of an artificial neural network based on experimental data are presented in Table V.

TABLE V

COMPARATIVE ANALYSIS OF ARTIFICIAL NEURAL NETWORKS' EFFICIENCIES IN SOLVING THE PROBLEM OF CLASSIFYING NON-NORMATIVE ERRORS

\begin{tabular}{|c|c|c|c|c|c|}
\hline \multirow[t]{2}{*}{ Predicted Value } & \multicolumn{5}{|c|}{ Probability of Correct Classification } \\
\hline & $\begin{array}{l}\text { Non-Normative } \\
\text { Errors Exist }\end{array}$ & $\begin{array}{c}\text { Non-Normative Errors } \\
\text { Do Not Exist }\end{array}$ & $\begin{array}{c}\text { Normative Errors } \\
\text { Exist }\end{array}$ & $\begin{array}{c}\text { Normative Errors } \\
\text { Do Not Exist }\end{array}$ & Total \\
\hline ANN $1 \times 1$ & $94.4 \%$ & $91.3 \%$ & $94.5 \%$ & $91 \%$ & $92.8 \%$ \\
\hline ANN $2 \times 1$ & $91.3 \%$ & $95 \%$ & $89.7 \%$ & $95.2 \%$ & $92.8 \%$ \\
\hline ANN $2 \times 2$ & $93.5 \%$ & $92.5 \%$ & $95.9 \%$ & $93.8 \%$ & $93.9 \%$ \\
\hline
\end{tabular}




\begin{tabular}{|c|c|c|c|c|c|}
\hline ANN $3 \times 3$ & $95.6 \%$ & $93.8 \%$ & $97.2 \%$ & $93.1 \%$ & $94.9 \% *$ \\
\hline ANN $4 \times 4$ & $93.5 \%$ & $93.8 \%$ & $95.9 \%$ & $93.8 \%$ & $94.3 \%$ \\
\hline ANN $5 \times 5$ & $92.4 \%$ & $93.8 \%$ & $95.9 \%$ & $93.8 \%$ & $93.9 \%$ \\
\hline ANN $6 \times 6$ & $92.4 \%$ & $93.8 \%$ & $94.5 \%$ & $93.8 \%$ & $93.7 \%$ \\
\hline
\end{tabular}

\section{Discussion}

On the basis of the data presented (string with asterisk in Table V), it can be concluded that the most optimal structure for an artificial neural network to ensure the controllability of the process variables for oil and gas equipment maintenance is a structure with three hidden layers, each with three neurons. Fig. 4 shows an error diagram in the learning process, and Fig. 5 presents a recognition accuracy diagram.

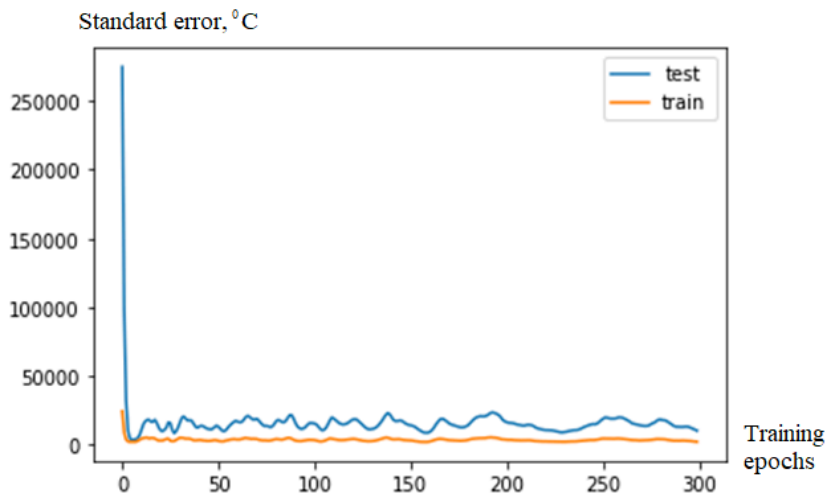

Fig. 4. Error diagram in artificial neural network learning

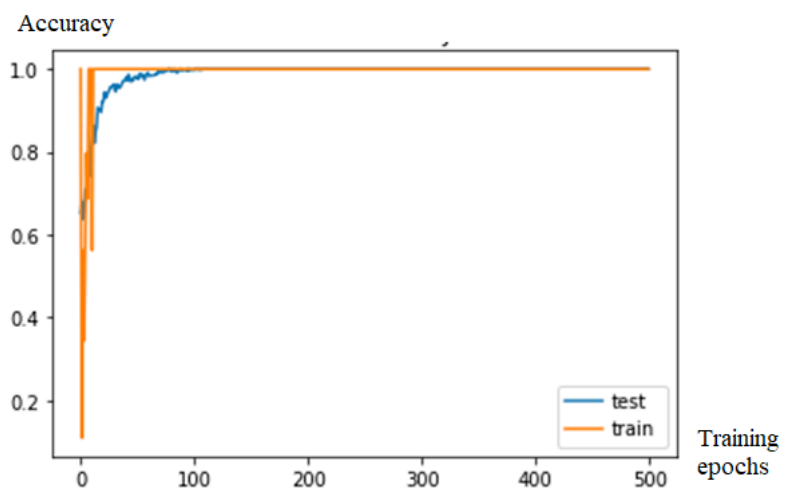

Fig. 5. Artificial neural network recognition accuracy diagram

As the diagrams show us, the method of classification of non-normative errors based on artificial neural networks shows a fairly high recognition accuracy of non-normative errors of measuring instruments. An artificial neural network with 3 hidden layers with 3 neurons on each layer showed recognition accuracy of $95.02 \%$. Artificial neural networks with other structures showed lower scores. The effectiveness of each classification method depends on its settings correctness. Concerning the presented methods an artificial neural network shows either the best efficiency with optimal structure or generally shows results higher than methods based on decision trees and fuzzy logic. Thus, we can conclude that the artificial neural network is a reliable method for ensuring the controllability of processes variables for oil and gas equipment maintenance

\section{Conclusion}

To ensure the controllability of process variables for oil and gas equipment maintenance three methods were chosen for comparative analysis: decision trees, artificial neural networks and fuzzy logic. The efficiency of the fuzzy logic and decision trees methods proved lower than that of artificial neural networks. The efficiency of methods based on fuzzy logic and decision trees was $80.08 \%$ and $80.52 \%$ respectively. The classification method based on artificial neural networks showed a better score $(95.02 \%$.). The artificial neural network with 3 hidden layers with 3 neurons showed classification accuracy of $95.02 \%$. Thus, artificial neural networks have proved themselves to be an efficient method of ensuring the controllability of process variables for equipment maintenance in the oil and gas industry. Using intelligent methods will improve the quality of repairs and the reliability of oil and gas equipment and, as a result, reduce the cost of hydrocarbon production and processing.

\section{References}

[1] Baskin Y (2012) Brazing of carbide mining tools. Coal Age 117(2):46-47

[2] Breiman L (2017) Classification and regression trees. Routledge, New York

[3] Ernens D, Hariharan H, Van Haaften WM, Pasaribu HR, Jabs M, McKim RN (2018) Improving casing integrity with induction brazing of casing connections. SPE Drilling and Completion 33(3):241-251

[4] Fausett L (1994) Fundamentals of neural networks: architectures, algorithms, and applications. Prentice Hall Inc., Englewood Cliffs, NJ

[5] Fominykh DS, Rezchikov AF, Kushnikov VA, Ivashchenko VA, Bogomolov AS, Filimonyuk LY, Dolinina ON, Kushnikov OV, Shulga TE, Tverdokhlebov VA (2018) Problem of quality assurance during metal constructions welding via robotic technological complexes. Journal of Physics: Conference Series 1015(3):032169

[6] Gierth P, Rebenklau L, Michaelis A (2012) Evaluation of soldering processes for high efficiency solar cells. 35th International Spring Seminar in Electronics Technology, pp 133137

[7] Hastie T, Tibshirani K, Friedman J (2009) The elements of statistical learning. Springer-Verlag, New York 
[8] Jordan MI, Rumelhart DE (1992) Forward models: supervised learning with a distal teacher. Cognitive Science 16(3):307-354

[9] Kersey AD (2000) Optical fiber sensors for permanent downwell monitoring applications in the oil and gas industry. IEICE Transactions on Electronic 83(3):400-404

[10] Klir G, Yuan B (1995) Fuzzy sets and fuzzy logic. Prentice Hall Inc., Englewood Cliffs, NJ

[11] Larose DT, Larose CD (2005) Discovering knowledge in data: an introduction to data mining. IEEE Computer Society, pp 90106

[12] Lippmann R (1987) An introduction to computing with neural nets. IEEE ASSP Magazine 4(2):4-22

[13] Loh WY (2011) Classification and regression trees. Wiley Interdisciplinary Reviews: Data Mining and Knowledge Discovery 1:14-23

[14] Mamdani EH, Assilian S (1975) An experiment in linguistic synthesis with a fuzzy logic controller. International Journal of Man-Machine Studies 7(1):1-13

[15] Mazón-Valadez E, Hernández-Sámano A, Estrada-Gutiérrez JC, Ávila-Paz J, Cano-González ME (2014) Developing a fast cordless soldering iron via induction heating. Dyna 81(188):166 173

[16] McCulloch WS, Pitts WH (1943) A logical calculus of the ideas immanent in nervous activity. Bulletin of Mathematical Biophysics 5:115-133

[17] McCulloch WS, Pitts WH (1945) A heterarchy of values determined by the topology of nervous nets. Bulletin of Mathematical Biophysics 7:89-93

[18] Mitchell T (1997) Machine learning. McGraw-Hill Education, New York

[19] Moiseeva LS (2005) Carbon dioxide corrosion of oil and gas field equipment. Protection of Metals 41:76-83

[20] Murygin AV, Tynchenko VS, Laptenok VD, Emilova OA, Bocharov AN (2017a) Complex of automated equipment and technologies for waveguides soldering using induction heating. IOP Conference Series: Materials Science and Engineering 173(1):012023

[21] Murygin AV, Tynchenko VS, Laptenok VD, Emilova OA, Seregin YN (2017b) Modeling of thermal processes in waveguide tracts induction soldering. IOP Conference Series: Materials Science and Engineering 173(1):012026

[22] Nasrabadi NM (2007) Pattern recognition and machine learning. Journal of Electronic Imaging 16(4):049901

[23] Nelson MM, Illingworth WT (1991) A practical guide to neural nets. Addison-Wesley, Reading, MA

[24] Nishimura F, Nakamura H, Takahashi H, Takamoto T (1992) Development of a new investment for high-frequency induction soldering. Dental Materials Journal 11(1):59-69

[25] Piovesan CM, Kozman JB (2014) Method, system and apparatus for intelligent management of oil and gas platform surface. Equipment. Patent 8676721 USA

[26] Queitsch Q (1975) Welding problems in pipelines, nominal Dia, 1420, steel quality X 65. Energietechnik 25(1):18-21

[27] Rahimi M, Rausand M, Wu S (2011) Reliability prediction of offshore oil and gas equipment for use in an arctic environment. International Conference on Quality, Reliability, Risk, Maintenance, and Safety Engineering, pp 81-86

[28] Ripley BD (1996) Pattern recognition and neural networks. Cambridge University Press, New York

[29] Tynchenko VS, Murygin AV, Emilova OA, Bocharov AN, Laptenok VD (2016) The automated system for technological process of spacecraft's waveguide paths soldering. IOP Conference Series: Materials Science and Engineering 155(1):012007

[30] Widrow B, Winter RG, Baxter RA (1988) Layered neural nets for pattern recognition. IEEE Transactions on Acoustics, Speech, and Signal Processin 36(7):1109-1118

[31] Witten I, Frank E, Hall M, Pal C (2016) Data mining: practical machine learning tools and techniques. Morgan Kaufmann, Burlington

[32] Yen J, Langari R (1999) Fuzzy logic: intelligence, control, and information. Prentice Hall Inc., Englewood Cliffs, NJ

[33] Zemenkova M, Shalay V, Zemenkov Yu, Kurushina E (2016) Improving the efficiency of administrative decision-making when monitoring reliability and safety of oil and gas equipment. MATEC Web of Conferences https://doi.org/10.1051/matecconf/20167307001 